\title{
Estudo de caso sobre ensino de Geociências em uma turma de ensino fundamental da rede privada de Duque de Caxias, RJ
}

Study CaSe about Geosciences teaching at a class Of fundamental education OF a PRIVATE SCHOOL From

Duque de CaXIas - RJ

Thatianne Castro Vieira ${ }^{1 *}$, Andrea Velloso ${ }^{1}$, Ana Paula de Castro Rodrigues ${ }^{2}$

1Universidade do Grande Rio "Prof. José de Souza Herdy", Rua Prof. José de Souza Herdy, 1160, Jd. Vinte e Cinco de Agosto, Duque de

Caxias, RJ. thatiannev@gmail.com

2 Universidade Federal Fluminense, Departamento de Geoquímica, Outeiro São João Baptista s/n Centro - Niterói, RJ.

ABSTRACT: This study involved a diagnosis about the teaching of geoscientific contents during the sixth year of a private elementary school, in Santa Cruz da Serra, Duque de Caxias-RJ. Questionnaires were applied to one teacher (Sciences) and 37 students. A qualitative evaluation of four different teaching methods on the water cycle was performed. Most of the students did not know what Geosciences were, however they showed high interest in universe, volcanism and Earth planet. Both teacher and students pointed out the biogeochemical cycles as the least interesting topic. Among the activities applied in the classroom during the water cycle class, play activities (game and educational model) generated more questions and interactions between teacher and students. Elementary school teachers, especially in Sciences and Geography, need to renew their knowledge and vary their teaching practices in order to provide better conditions for learning Geosciences.
Manuscrito:

Recebido: 15/08/2015

Corrigido: $16 / 03 / 2016$

Aceito: 20/04/2016

Citation: Vieira T.C., Velloso A., Rodrigues A.P.C. 2016. Estudo de caso sobre ensino de Geociências em uma turma de ensino fundamental da rede privada de Duque de Caxias, RJ. Terræ Didatica, 12(3):153-162. $<$ http://www.ige.unicamp.br/terraedidatica/>.

Keywords: Geosciences, teaching and learning, teaching resources

\section{Introdução}

As Geociências, ou Ciências da Terra, envolvem todas as ciências que estudam o planeta Terra, incluindo geosfera, hidrosfera, atmosfera, biosfera e recentemente a antroposfera. Os temas geocientíficos fazem parte dos Parâmetros Curriculares Nacionais (PCN), além de serem abordados em diversas ocasiões, como por exemplo, em programas e políticas de educação e para a formação de professores (Frodeman \& Turner 1996, Orion et al. 1996, Orion 2001, Marques \& Praia 2001). Entretanto, no Brasil esses conteúdos estão fragmentados nas disciplinas de Ciências, História e Geografia, causando dificuldades aos docentes e discentes (Bacci et al. 2013, Compiani 1996, Carneiro et al. 2004, Guimarães 2004, Toledo et al. 2005).

Weissmann (1998) diz que os professores precisam possuir domínio dos conhecimentos que serão passados para os alunos para, então, poder medir a construção de conhecimento destes: "Um dos principais obstáculos no momento de querer ensinar é a falta de domínio e atualização dos professores no que se refere aos conteúdos escolares. Não há proposta didática inovadora e eventualmente bem sucedida que possa superar a falta de conhecimentos do professor".

Segundo Piranha \& Carneiro (2009), as geociências contribuem para a formação de uma Cultura de Sustentabilidade, e isso tem sido reforçado em diversas oportunidades. O Ano Internacional do Planeta Terra (Berbert 2006, Figueiredo 2007) foi um exemplo. Apesar disso, pesquisas apontam que a maioria do corpo discente cursando o ensino fundamental II de uma instituição de ensino, na zona norte da cidade do Rio de Janeiro (RJ) não sabe o que é geociências e demonstram interesse médio na maioria dos temas geocientíficos pesquisados por Firmino (2013).

É notória a necessidade dos docentes de elaborar aulas dinâmicas, ressaltando o cotidiano dos 
discentes dentro da sala de aula. Segundo Jesus (2010) "através da atividade lúdica e do jogo, a criança forma conceitos, seleciona ideias, estabelece relações lógicas, integra percepções, faz estimativas compatíveis com o crescimento físico e desenvolvimento e, o que é mais importante, vai socializando". Desta forma, a diversificação dos recursos didáticos é de suma importância para a melhora da aprendizagem em qualquer faixa etária.

Os PCN vêm discutindo a inclusão de novos métodos eficazes para o ensino, que possam estimular a busca de diferentes atividades e explorar o meio ambiente em uma abordagem multidisciplinar (BRASIL 1998). Bianconi \& Caruso (2005) citam como atividades a serem incluídas em aulas formais: jogos, experimentos e vídeos. Silva et al. (2012) dizem que utilizar recursos didáticos variados melhoram a aprendizagem, além de preencher certas lacunas do ensino tradicional, porém não são todos os professores que estão preparados para utilizá-los.

Lopes \& Carneiro (2009) criaram o jogo "O ciclo das Rochas", sendo capaz de atingir diferentes tipos de público-alvo (ensino básico e superior). Usando a adaptação do jogo para o ensino superior, os autores aplicaram o jogo na turma do primeiro ano (turno noite) do curso Ciências da Terra da Unicamp em 2006, onde obtiveram um resultado bastante satisfatório, pois as primeiras experiências revelaram que o modelo é instigante e pode despertar grande interesse pelo tema.

Segundo Seniciato \& Cavassan (2004) a inclusão de aulas em ambientes naturais supera a fragmentação dos conteúdos, além de mudar conceitos e posturas dos discentes em relação ao meio ambiente. Um exemplo é o projeto "Observação de Aves como Ferramenta Didática nas Aulas de Ciências", que foi desenvolvido com a participação de 40 alunos de turmas da $1^{\mathrm{a}}$ a $3^{\mathrm{a}}$ série do Ensino Médio, na Escola Estadual Dr. Augusto do Nascimento e Silva, localizada em Santo Ângelo, no Rio Grande do Sul, em agosto de 2011 (Oliveira et al. 2012). Através desse projeto Oliveira et al. (2012) consideraram esse método de ensino relevante para a aprendizagem dos discentes, pois perceberam que houve um grande interesse de explorar o ambiente, analisar as diversas interações que ocorrem na natureza, perceberam que o equilíbrio do planeta depende das nossas atitudes e relacionaram diversos questionamentos. Entretanto, observa-se a predominância das aulas expositivas em salas de aula formais (Firmino 2013).

\section{Objetivos}

O presente estudo teve como objetivo realizar um diagnóstico sobre o ensino de temas geocientíficos no sexto ano do ensino fundamental II em uma turma de instituição educacional pertencente à rede privada, localizada em Santa Cruz da Serra, Duque de Caxias-RJ. Objetivou-se também descrever os diferentes níveis de interesse e comportamentos do corpo discente em relação a três diferentes recursos didáticos utilizados em sala de aula formal, como complemento à aula expositiva. A princípio optou-se pelo sexto ano do ensino fundamental II, por ser a série em que o conteúdo do currículo mínimo de Ciências é voltado para o conhecimento do planeta e seu funcionamento. Além disso, o docente de Ciências foi entrevistado para traçar o perfil do profissional e identificar os recursos didáticos mais utilizados pelo mesmo no ensino de Geociências.

A escola onde o estudo foi desenvolvido está localizada no município de Duque de Caxias, pertencente ao Estado do Rio de Janeiro (Brasil). Em 2014, este município possuía aproximadamente 878.402 habitantes (Instituto Brasileiro de Geografia e Estatística - IBGE 2015). Em 2012, o quadro docente do município para Ensino Fundamental era de 6.229 professores, distribuídos em 369 escolas, incluindo as da rede pública e privada (IBGE 2015). Os Ministérios Públicos Federal (MPF) e do Estado do Rio de Janeiro (MP-RJ) realizaram a primeira audiência no dia 21 de Janeiro de 2015 para debater a qualidade e o baixo rendimento do ensino básico de Duque de Caxias (EBC Agência Brasil 2015). O Índice da Educação Básica (IDEB) em 2013 variou entre 3,3 nos anos finais e 4,4 nos anos iniciais, porém o ideal era possuir uma nota mínima igual a 6 , referente a escala de 0 a 10.

\section{Materiais, métodos e técnicas}

A presente pesquisa foi realizada durante o primeiro semestre de 2015, na turma 604 do turno da tarde, do sexto ano do ensino fundamental II, na disciplina de Ciências, em um colégio da rede privada, localizado no bairro de Santa Cruz da Serra, Duque de Caxias, RJ. Optou-se por uma análise investigativo-exploratória, um estudo de caso, onde foram utilizados, para a obtenção dos dados, questionários contendo perguntas abertas e fechadas para o corpo docente (Fig. 1) e o discente (Fig. 2), utilizando como base os trabalhos de 
1 - Em específico, há quantos anos leciona para alunos do Ensino Fundamental?

2 - Qual(is) a(s) maior(es) dificuldade(s) já encontrada(s) durante esses anos de prática de ensino/aprendizagem aplicada aos alunos do Ensino Fundamental?

3 - Possui graduação na disciplina que ministra?

4 - Procura fazer uma ligação dos temas relacionados às Geociências com os fatos da realidade?

5 - Qual o grau de interesse dos alunos para determinados conteúdos de Geociências?

Origem do universo:

Planeta Terra:

( ) Alto ( ) Médio ( ) Baixo ( ) Nenhum

() Alto () Médio () Baixo () Nenhum
() Alto () Médio () Baixo () Nenhum Ciclos Biogeoquímicos:

Vulcanismo:

Ciclo das Rochas:

Clima:

Relevo:

Biomas:

( ) Alto ( ) Médio ( ) Baixo ( ) Nenhum

( ) Alto ( ) Médio ( ) Baixo ( ) Nenhum

( ) Alto ( ) Médio ( ) Baixo ( ) Nenhum

( ) Alto ( ) Médio ( ) Baixo () Nenhum

( ) Alto ( ) Médio ( ) Baixo ( ) Nenhum

Paisagens vegetais:

Bacias Hidrográficas:

Uso do Solo:

Mapa temático:

( ) Alto ( ) Médio ( ) Baixo ( ) Nenhum

( ) Alto ( ) Médio ( ) Baixo ( ) Nenhum

( ) Alto ( ) Médio ( ) Baixo ( ) Nenhum

( ) Alto ( ) Médio ( ) Baixo ( ) Nenhum Impactos ambientais:

() Alto ( ) Médio () Baixo () Nenhum

6 - Quais temas relacionados a Geociências possuem maior dificuldade de aprendizado por parte dos alunos?

7 - Você procura ministrar suas aulas por outros meios, que não sejam somente através de livros didáticos e explanação oral em sala?

8 - Caso não use nenhum recurso didático. Por que não utiliza recursos didáticos?

9 - Com base na pergunta anterior quais os meios que utiliza com mais frequência?

10 - A escola disponibiliza locais propícios, excursões didáticas e materiais para a realização desses recursos?

Figura 1. Questionário aplicado ao docente de Ciências, em Instituição de Ensino da rede privada, em Santa Cruz da Serra, Duque de Caxias, RJ.

Firmino (2013) e Menezes (2013). O corpo docente foi composto por apenas um docente de Ciências, que lecionava para todas as turmas de sexto ano da instituição (04 turmas - duas no turno manhã e duas no turno tarde, que totalizam 203 alunos) e o corpo discente incluído nesta pesquisa foi de 37 alunos (todos os alunos da turma 604), na faixa etária entre 10 e 13 anos. Para a análise dos dados foi utilizado o programa Microsoft Excel 2007. A identidade do docente e dos alunos entrevistados foi preservada.

E para avaliar o comportamento, o interesse e a participação da turma de acordo com o tipo de prática de ensino aplicada, foi utilizado um questionário de uso exclusivo para anotações dos pesquisadores (Fig. 3), em que foram escritas as principais dificuldades durante o uso dos quatro diferentes recursos didáticos. As diferentes atividades aplicadas foram:Atividade 1: Primeiramente uma apresentação sobre o que seria feito na aula foi realizada, explicando as atividades do dia e o conteúdo a ser abordado (ciclo da água). A primeira atividade foi uma aula expositiva, utilizando uma apresentação preparada no programa Microsoft
Power Point 2007 e projetada com o auxílio de Datashow. A aula expositiva incluiu uma pequena revisão sobre os estados físicos da água, seguindo para o tema específico da aula, o ciclo da água.

Atividade 2: No final da aula expositiva, a atividade número 2 foi assistir ao vídeo "O Ciclo da Água”, disponibilizado pela Agência Nacional de Águas (https://www.youtube.com/watch?v=vW5 -xrV3Bq4), onde foi possível observar de modo ilustrativo e mais dinâmico como este ciclo ocorre.

Atividade 3: Após o vídeo, para a terceira atividade, a turma foi separada em nove grupos, contendo no mínimo quatro e no máximo cinco integrantes, para a observação do ciclo curto da água em um modelo didático (terrário). Os modelos foram repassados aos alunos já prontos e para a preparação foram utilizados recipientes recicláveis transparentes (pote de maionese e de azeitona), para montar as diferentes camadas contendo: fragmentos de rochas; carvão vegetal; terra adubada, briófitas e monocotiledôneas. Após montagem, foi colocado cerca de $50 \mathrm{~mL}$ de água nos recipientes, sendo estes fechados com tampa.

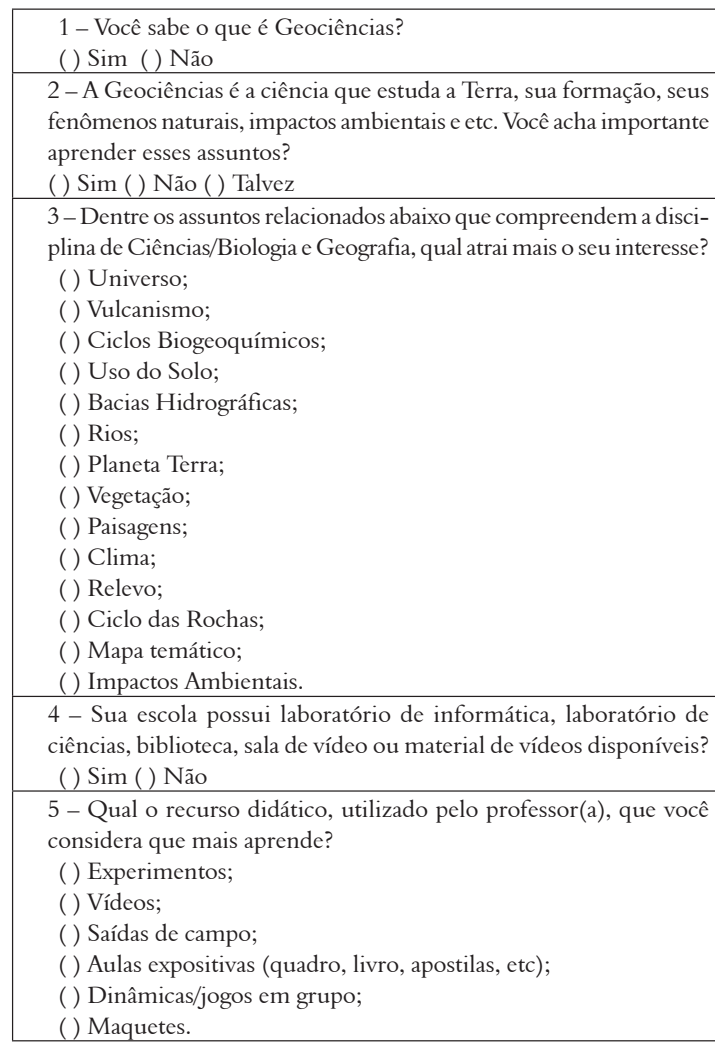

Figura 2. Questionário aplicado para os estudantes da turma 604, sexto ano do ensino fundamental II,de uma Instituição de Ensino da rede privada, em Santa Cruz da Serra, Duque de Caxias, RJ. 
Atividade 4: Por último foi aplicado um jogo sobre o ciclo da água elaborado pelos pesquisadores. O jogo é composto por um painel e cartas. Para poder estimular o trabalho em equipe, os grupos formados para a atividade três foram mantidos, sendo assim foram elaborados nove painéis ao todo. Os painéis foram elaborados pelos pesquisadores com materiais de baixo custo, sendo eles: papel quarenta quilos; folha tamanho A4; cola e tesoura. Primeiramente foi escolhida uma imagem do ciclo da água e a partir dela foram realizadas adaptações para a criação de lacunas em cada etapa do ciclo da água, para que os alunos pudessem completá-las a partir dos conceitos trabalhados em sala de aula. Essa adaptação foi realizada com o auxílio do programa Microsoft Power Point 2007. A imagem foi impressa com cinquenta e quatro centímetros de largura e sessenta e cinco centímetros de altura, a partir do programa Posteriza. Após a impressão da imagem, ela foi colada no papel quarenta quilos. Para a elaboração das cartas, contendo as respostas das lacunas, foi utilizado o programa Microsoft Word 2007. O objetivo do jogo era preencher os espaços vazios corretamente, cada lacuna representava uma etapa do ciclo da água, sendo assim o grupo que terminasse primeiro de preencher e estivesse tudo correto, era o grupo vencedor.

\begin{tabular}{|l|}
\hline 1-Quantos alunos estavam presentes no dia da aula? \\
\hline 2-Qual a faixa etária dos alunos? \\
\hline 3-Qual o perfil da turma na escola? \\
\hline 4- Os alunos mostraram interesse durante a aula? \\
\hline 5- Em qual método os alunos mostraram mais interesse? \\
\hline 6- Como foi a participação dos alunos no método do lúdi- \\
co? Houve organização? A aplicação do método ocorreu de \\
forma esperada? \\
\hline $\begin{array}{l}\text { 7-Qual foi o modelo didático utilizado? Eles demonstraram } \\
\text { interesse e curiosidade ao ver o modelo? }\end{array}$ \\
\hline 8- Qual foi o comportamento da turma durante a aula? \\
\hline
\end{tabular}

Figura 3. Questionário de uso exclusivo dos pesquisadores para a avaliação do comportamento, interesse e participação da turma de sexto ano do ensino fundamental II, diante de quatro diferentes atividades sobre o ciclo da água.

\section{Apresentação de dados}

\section{Questionário ao corpo docente}

As respostas do docente às perguntas abertas podem ser observadas na tabela 1 . O docente possui graduação em Ciências Biológicas. Leciona há 20 anos e durante todo esse tempo, apontou como a sua maior dificuldade a falta de comprometimento e ajuda dos pais dos alunos. Em relação a como aborda os temas geocientíficos em suas aulas, o docente relatou que procura fazer sempre ligações com o cotidiano dos alunos e ainda que dentre todos os conteúdos do currículo mínimo que estão diretamente ligados às Geociências, os ciclos biogeoquímicos são os que apresentam maior dificuldade de aprendizagem pelos alunos.

Sempre que possível, o docente relatou usar o auxílio de outros recursos didáticos, em especial, apresentações com projeção em Datashow e relata que a instituição de ensino disponibiliza locais propícios para atividades práticas, organiza excursões didáticas e fornece materiais necessários para o uso de diferentes recursos didáticos.

Tabela 1. Respostas do docente da disciplina de Ciências às perguntas abertas

\begin{tabular}{|c|c|}
\hline Perguntas abertas & Respostas \\
\hline $\begin{array}{l}\text { Em específico, há quantos anos } \\
\text { leciona para alunos do ensino fun- } \\
\text { damental? }\end{array}$ & 20 anos \\
\hline $\begin{array}{l}\text { Qual(is) a (s) maior(es) } \\
\text { dificuldade(s) já encontrada(s) } \\
\text { durante esses anos de prática de } \\
\text { ensino/aprendizagem aplicada aos } \\
\text { alunos de Ensino Fundamental? }\end{array}$ & $\begin{array}{l}\text { A falta de compro- } \\
\text { metimento e ajuda } \\
\text { dos pais }\end{array}$ \\
\hline $\begin{array}{l}\text { Possui graduação na disciplina que } \\
\text { ministra? }\end{array}$ & Sim \\
\hline $\begin{array}{l}\text { Procura fazer uma ligação dos temas } \\
\text { relacionados às geociências com os } \\
\text { fatos da realidade? }\end{array}$ & $\operatorname{Sim}$ \\
\hline $\begin{array}{l}\text { Quais temas relacionados a } \\
\text { Geociências possuem maior difi- } \\
\text { culdade de aprendizado por parte } \\
\text { dos alunos? }\end{array}$ & $\begin{array}{l}\text { Ciclos } \\
\text { biogeoquímicos }\end{array}$ \\
\hline $\begin{array}{l}\text { Você procura ministrar suas aulas } \\
\text { por outros meios, que não sejam } \\
\text { somente através de livros didáticos } \\
\text { e explanação oral em sala? }\end{array}$ & $\begin{array}{l}\text { Sim, sempre que } \\
\text { possível }\end{array}$ \\
\hline $\begin{array}{l}\text { Caso não use nenhum recurso didá- } \\
\text { tico. Por que não utiliza recursos } \\
\text { didáticos? }\end{array}$ & $\mathrm{X}$ \\
\hline $\begin{array}{l}\text { Com base na pergunta anterior, } \\
\text { quais os meios que utiliza com mais } \\
\text { frequência? }\end{array}$ & Datashow \\
\hline $\begin{array}{l}\text { A escola disponibiliza locais propí- } \\
\text { cios, excursões didáticas e materiais } \\
\text { para realização desses recursos? }\end{array}$ & Sim \\
\hline
\end{tabular}


Em relação à pergunta fechada, o docente avaliou como interesse alto, quatro dos doze temas propostos no questionário (Planeta Terra, Vulcanismo, Bacias Hidrográficas e Uso do Solo), como médio, sete dos doze temas (Universo, Ciclo das Rochas, Clima, Relevo, Paisagens Vegetais, Mapa Temático e Impactos Ambientais), como baixo, apenas 1 tema (Ciclos Biogeoquímicos) e nenhum tema foi classificado como desinteressante para os alunos.

\section{Questionário ao corpo discente}

Em pergunta fechada, com as opções "sim" e "não", a maioria dos estudantes afirmou não saber o que significa Geociências (70,3\%). Porém a grande maioria dos alunos acha importante aprender temas relacionados a Geociências (86,5\%). Esta segunda pergunta, também fechada, com opções de "sim", "não" e "talvez", pode ser respondida até mesmo pelos estudantes que afirmaram não saber o que era geociências, pois na própria pergunta estavam presentes alguns exemplos de temas geocientíficos. Dentre os 13,5\% restantes, 10,8\% dos alunos apresentaram dúvidas quanto à importância das Geociências, respondendo "talvez" para esta questão e apenas 2,7\% respondeu "não".

Conforme apresentado na figura 4 , que representa a pergunta fechada: Dentre os assuntos relacionados abaixo que compreendem as disciplinas de Ciências/Biologia e Geografia, qual atrai mais o seu interesse? pode-se observar que a maioria dos alunos $(>60,0 \%)$ possui interesse em Universo, Vulcanismo e Planeta de Terra. Enquanto os Ciclos Biogeoquímicos e os Mapas Temáticos foram considerados como temas interessantes por menos de $10 \%$ dos alunos entrevistados.

Para a questão fechada Qual recurso didático, utilizado pelo professor, que você considera que mais aprende? $37,8 \%$ dos alunos consideraram as aulas expositivas a melhor forma de aprender, seguindo de experimentos $(35,1 \%)$ e vídeos $(32,4 \%)$. Um menor grupo de alunos acredita que o uso de saída de campo (16,2\%), dinâmica/jogos em grupo $(21,6 \%)$ e maquete $(10,8 \%)$ seja a melhor forma de aprender. É importante informar que os alunos poderiam assinalar todos os recursos didáticos que eles consideram importantes, podendo marcar mais de uma opção para a mesma questão. Assim, os percentuais demonstrados compreendem no número de vezes que cada recurso didático foi indicado como importante dividido pelo número total de alunos entrevistados.

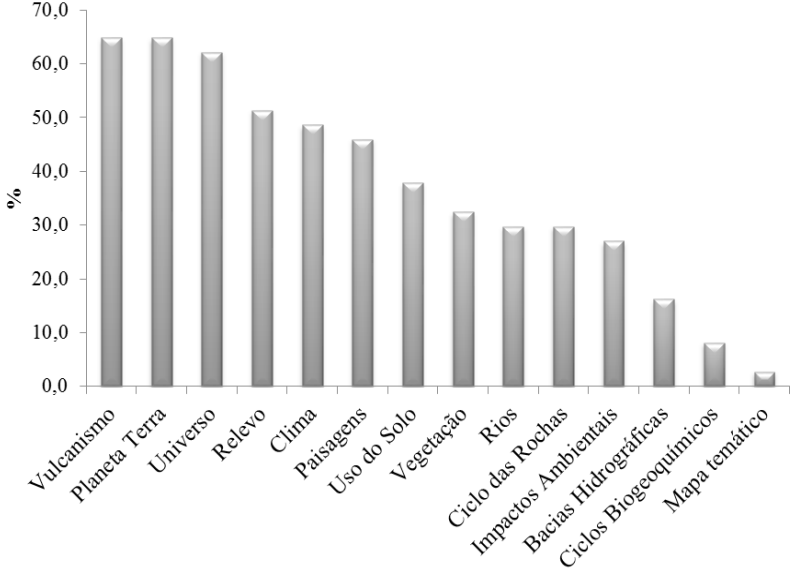

Figura 4. Percentual de alunos do sexto ano do ensino fundamental II de uma instituição de ensino da rede privada, em Santa Cruz da Serra, Duque de Caxias-RJ, que classificaram como interessantes os temas geocientíficos propostos no questionário.

\section{Análise do comportamento, do interesse e da participação da turma}

Os alunos que compõem a turma 604 do $6^{\mathrm{O}}$ ano avaliada neste estudo de caso são considerados como "agitados" pelo corpo docente da instituição. Entretanto, mesmo durante a atividade 1 (aula expositiva), que teve duração de 30 minutos, cerca de 10 alunos mostraram interesse no assunto realizando questionamentos. Alguns exemplos dos questionamentos feitos durante a aula são: "O que seria condensação?", "Como ocorre a precipitação?" $e$ "Se a água subterrânea estiver contaminada no local de um poço nós podemos pegar alguma doença?”. Apesar da maioria dos alunos não apresentar uma interação maior com o docente, eles demonstraram atenção durante a explicação, não dispersando.

Durante a atividade 2, com 3 minutos de duração, foi obtido interesse total dos alunos, onde os mesmos prestaram atenção, de uma forma divertida e descontraída. Tanto a aula com o auxílio do Datashow como a apresentação do vídeo não apresentaram dificuldades aparentes para o entendimento do conteúdo pelos discentes, mostrando, então, serem recursos didáticos de fácil aplicação e compreensão.

Durante a atividade 3, foi necessária a separação da turma em grupos, causando tumulto, fazendo com que os alunos ficassem agitados e perdendo tempo da aula. Até organizar todos os grupos em seus devidos lugares levou-se cerca de 10 minutos, gastando mais 20 minutos para a aplicação desse método. Esse tempo gasto para a organização de grupos é considerado alto, demonstrando que 
a turma ainda não possui grupos essencialmente formados, prolongando o tempo necessário para decidir "quem fica com quem". Ao distribuir o modelo didático do terrário, os alunos, todos de uma vez só, começaram a fazer as seguintes perguntas: "Como você fez isso?", "Isso aqui é carvão?", "Tem algum bicho?", "Você colocou água aqui dentro?", "Isso é musgo? Por que você colocou musgo?" e "Está embaçado porque a água evaporou?". Este foi um ponto positivo da atividade, pois esta fez despertar curiosidades importantes para o entendimento do modelo e do ciclo da água em si. Após a "chuva" de perguntas, foi possível explicar como o modelo foi feito e como funcionava aquele ecossistema fechado, falando sobre o ciclo curto da água.

$\mathrm{Na}$ atividade 4 , similarmente à atividade 3 , a turma ficou muito agitada enquanto o material do jogo era distribuído. Levando, novamente, cerca de 10 minutos até retornar o foco da turma para explicação das regras do jogo. Os alunos mostraram bastante interesse e entusiasmo com o jogo, mesmo com o comportamento agitado. Após finalizar a atividade e ter o grupo vencedor, foi analisado se eles preencheram de forma correta as lacunas que representavam o ciclo da água. A grande maioria dos grupos inverteu condensação com precipitação ou condensação com evaporação. A aplicação do jogo levou cerca de 20 minutos, incluindo os 10 minutos usados para a organização dos grupos. Sendo assim, foi concluído que a maior dificuldade encontrada foi a organização da turma para a realização da observação do modelo didático e do método lúdico. Porém foram as duas atividades que mais estimularam perguntas e a participação dos alunos. Adicionalmente, a atividade lúdica pode também servir de retorno sobre a compreensão do tema por parte dos alunos a partir da avaliação de respostas certas e erradas, conseguindo identificar termos que não haviam sido compreendidos até o momento.

\section{Discussão e interpretação dos resultados}

A maioria dos alunos afirmou não saber o que era Geociências. O mesmo foi observado por Menezes (2013), que trabalhou com turmas do $6^{\circ}$ ao $9^{\circ}$ anos do Ensino Fundamental II, em uma instituição de ensino da rede privada, no município do Rio de Janeiro-RJ, mostrando que mais da metade dos alunos entrevistados não sabia o que era Geociências e mesmo aqueles que diziam saber, na hora de descrever uma definição para o termo em uma pergunta aberta, eles apresentaram respostas incorretas ou incompletas. No presente trabalho, os alunos não escreveram a definição de geociências, apenas marcaram em uma pergunta fechada se sabiam ou não o que esse termo significava.

Para Carneiro et al. (2004) existem várias razões para a inclusão desse assunto no ensino básico, como criar raciocínio crítico e trazer questões atuais e de importância no nosso cotidiano para discussão, como por exemplo, sustentabilidade e os recursos naturais do nosso planeta. Assim como a maioria dos alunos acredita ser importante o ensino dos temas relacionados a Geociências, Galvão \& Finco (2009) realizaram um trabalho baseado na importância da inclusão dos temas de Geociências nas disciplinas do Ensino Médio e apontam que o ensino de disciplinas científicas, em visão geral, é de grande importância. Porém ultimamente esses temas vêm sendo tratados de forma desestimulante, como se fosse algo velho, sem novas descobertas. Entretanto, entender as Geociências é entender o funcionamento do planeta e perceber o homem como ser capaz de modificar o meio em que vive:"as atividades humanas e a dinâmica natural - determinam que as questões de natureza ambiental passem a integrar o corpo de conhecimentos básicos que uma pessoa deveria possuir, para exercer, ao longo de sua vida, aquilo que se entende por cidadania responsável e consequente." (Carneiro et al. 2004).

Em relação aos temas classificados pelos alunos como interessantes, Planeta Terra, Vulcanismo, Universo, Relevo e Clima foram os mais citados. Firmino (2013) realizou uma pesquisa, aplicando a mesma questão para turmas do Ensino Médio, e obteve um resultado parecido com os interesses da turma do $6^{\circ}$ ano investigada, onde o tema Universo foi o que mais teve interesse da parte dos alunos, seguido de Paisagens, Impactos Ambientais, Planeta Terra e Vulcanismo. Rios \& Chaves (2011) elaboraram uma pesquisa na qual os temas Relevo, Solos e Vegetação foram considerados os mais fáceis e devido isso os que mais atraiam os alunos. Para o autor, não ocorre interesse em outros temas, considerados com níveis de dificuldades maiores, pois a forma como são abordados e ministrados, incluindo a falta da diversidade de recursos didáticos, não causa atração para os alunos, sendo assim, acaba criando um efeito contrário. $\mathrm{O}$ uso de recursos didáticos variados para esses temas relatados como de baixo interesse é importantíssimo, para que esses temas se tornem mais atrativos e para facilitar o processo de ensino/aprendizagem. 
Segundo o docente entrevistado no presente estudo, o grau de interesse dos alunos do $6^{\circ}$ ano do Ensino Fundamental II em relação aos temas de Geociências varia entre alto e médio, sendo apontado como baixo interesse apenas o tema Ciclos Biogeoquímicos. Em uma pesquisa similar com professores do Ensino Médio de uma escola da rede privada da cidade do Rio de Janeiro, os docentes descreveram o interesse dos alunos por temas geocientíficos como médio / baixo, citando também ciclos biogeoquímicos como um tema incapaz de despertar o interesse dos estudantes (Firmino 2013). Isso corrobora a necessidade da inclusão dos temas de Geociências logo no começo do Ensino Básico, formando então, conforme Carneiro et al. (2004) aponta, cidadãos com o raciocínio crítico, mostrando as questões atuais do planeta Terra, além de estimular a formação de pensamentos científicos nos alunos que ainda estão em processo de formação.

Imbernon et al. (1994) verificaram um aumento nas últimas décadas no ensino de Geociências nos programas ministrados no ensino básico no Brasil, onde na década de 50 era oferecido apenas $20 \%$ do conteúdo e ainda na década de 80 aumentou para $40 \%$. Mesmo com esse aumento, não foi possível obter uma boa compreensão dos alunos com relação ao planeta Terra, o seu funcionamento e os seus materiais. Toledo et al. (2005) aponta que os conteúdos geocientíficos, com raras exceções, são ministrados de forma fragmentada, dispersa e desatualizada, não causando uma compreensão adequada da Terra como um sistema complexo e dinâmico, assim mesmo com uma maior inserção destes nos conteúdos do currículo mínimo, não há uma consideração quando por exemplo a adequação de currículos de cursos de graduação para formação de professores. Imbernon et al. (1994) observaram na década de 1990 que os professores não possuíam o domínio do conteúdo, causando, então, uma deficiência no ensino, além de um ensino fragmentado e desinteressante. Problema este persistente nos anos 2000, como relatado por Oliveira et al. (2012), que afirmou que os professores envolvidos em seu estudo não tiveram oportunidade de acesso ou até mesmo a formação adequada nos temas geológicos.

Oliveira et al. (2012) aponta que mesmo estando presentes os conteúdos de Geociências nos currículos escolares, é necessário uma preparação do docente para esses conteúdos serem ministrados corretamente. Pois para Augusto \& Amaral (2014), os conteúdos e teorias científicas não bastam para o ensino dos conteúdos de Ciências, além disso, é necessário que os professores "conheçam a história das Ciências; o processo de produção dos conhecimentos científicos; as relações entre Ciência, Tecnologia, Sociedade e Ambiente; os avanços atuais da Ciência; saibam selecionar os conteúdos adequados ao nível de escolaridade e possam continuar aprendendo permanentemente" e nas séries iniciais de Ciências é preciso que a formação dos professores supere "a fragmentação existente nos cursos entre áreas específicas e pedagógicas e intensificar a relação teoria-prática" (Silva 1998).

Os alunos escolheram as aulas expositivas como o melhor recurso didático utilizado pelo docente para que eles aprendessem algum assunto. Por sua vez, os alunos indicam as saídas de campo e as maquetes como os recursos que eles menos aprendem. Entretanto essa resposta pode estar vinculada ao fato do docente não utilizar outros recursos didáticos além das aulas expositivas. Sendo assim os alunos não possuem conhecimento prévio suficiente para avaliar a eficácia e os ganhos de outras atividades para a construção do conhecimento.

Como todas as escolas públicas do Estado do Rio de Janeiro ganharam projetores de slides nos últimos anos, o recurso didático apontado como mais utilizado, além da aula expositiva em quadro, foi o Datashow. A utilização de outros recursos didáticos foi apontada como "sempre que possível" pelo docente. Entretanto, segundo informações obtidas durante a vivência na instituição de ensino, foi possível observar que durante todo o semestre o docente na verdade reservou o projetor somente uma vez. E mesmo assim o recurso de projeção em Datashow foi utilizado não para uma aula preparada pelo docente, mas para apresentação de trabalho pelos discentes.

Em uma pesquisa realizada por França (2009), os professores entrevistados indicaram saber a importância e as funções da utilização de recursos didáticos, porém, em contrapartida, os mesmos apresentaram não saber utilizar esses recursos nos momentos corretos, mostrando que houve controvérsia em relação às respostas obtidas na entrevista. A falta de conhecimento e de preparação do professor pode levar a pouca variação no uso de recursos didáticos. Fraser \& Gondim (2004) realizaram um trabalho onde afirmaram que a entrevista dá a oportunidade do entrevistado dizer o que está acessível em sua mente. Pois quando a pesquisa está relacionada à investigação, não pode 
levar em consideração apenas o que os entrevistados falam, deve ocorrer, também, a observação, permitindo obter uma conclusão concreta do que ocorre.

Firmino (2013) aponta, em ordem crescente de uso, os recursos didáticos mais utilizados pelos professores entrevistados na zona Oeste da cidade do Rio de Janeiro-RJ: Vídeos; Datashow; Maquetes; Experimentos; Jogos/Dinâmica; Mapas; Aulas de Campo; Laboratório de Ciências; Jogos Online; Laboratório de Informática. Enquanto isso, os alunos de ensino médio entrevistados responderam que a forma que eles consideram aprender mais, em relação aos recursos didáticos é em ordem decrescente: Experimento; Datashow; Vídeos; Jogos/Dinâmicas; Saída de Campo; Aulas expositivas; Maquetes; Uso de Mapas. Por meio da análise desses resultados obtidos por Firmino (2013) é possível ver que as respostas dos alunos estão dentro dos 5 recursos mais utilizados pelos professores, sendo diferentes dos obtidos para este estudo de caso em outro município do Estado do Rio de Janeiro.

O docente apontou como o tema que os alunos apresentam menor interesse para aprender os ciclos biogeoguímicos. É possível observar que houve uma discordância entre a opinião do docente e as observações realizadas nas atividades de 1 a 4 aplicadas na turma, visto que todas as atividades foram sobre um dos ciclos biogeoquímicos. Inclusive os alunos mostraram grande interesse e curiosidades durante a aplicação de todos os recursos didáticos testados. Oliveira \& Trivelato (2006) afirmam sobre a utilização dos recursos didáticos: "a utilização de recursos didáticos pedagógicos diferentes dos utilizados pela maioria dos professores (quadro e giz), deixam os educandos mais interessados em aprender". Sendo assim Souza (2007) e Costoldi \& Polinarski (2009) afirmam que: "o professor deve ter formação e competência para utilizar os recursos didático-pedagógicos que estão ao seu alcance e muita criatividade, ou até mesmo construir juntamente com os alunos, pois, ao manipular esses objetos a criança tem a possibilidade de assimilar melhor o conteúdo. Os recursos didáticos não devem ser utilizados de qualquer jeito, deve haver um planejamento por parte do professor, que deverá saber como utilizá-lo para alcançar o objetivo proposto por sua disciplina". Assim a falta de interesse que os alunos acreditam ter em relação a certos temas geocientíficos pode ocorrer devido a forma que esses temas são abordados. Isto pode ser gerenciado com um maior tempo destinado a preparação das aulas, para que o conteúdo a ser ministrado seja trabalhado da melhor forma possí- vel para a faixa etária, utilizando a criatividade para relacionar esses temas com fatos da realidade e com os recursos didáticos correspondentes ao assunto.

\section{Considerações finais}

Com o presente estudo foi possível perceber que o termo geociências não é conhecido pela maioria dos estudantes, apesar de apresentarem alto interesse em temas como Universo, Vulcanismo e Planeta de Terra. Com relação aos temas considerados como menos interessantes (ciclos biogeoquímicos e mapas temáticos), as observações deste estudo de caso sugerem que o baixo interesse provém da falta de diversificação de recursos didáticos, visto que as atividades realizadas com a turma em estudo despertaram o interesse pelo ciclo biogeoquímico da água, obtendo-se um retorno positivo dos educandos. Outro ponto importante observado foi a discrepância entre as observações realizadas em turma durante o semestre e as respostas do docente responsável pela disciplina de Ciências, especialmente no que concerne ao uso de recursos didáticos.

Sugere-se então que há a necessidade de que os professores das séries do ensino fundamental II, em especial os responsáveis pela disciplina de Ciências (foco deste trabalho), se atualizem dentro dos assuntos abordados em sala de aula, sempre relacionando os temas falados com o cotidiano dos alunos. Adicionalmente, a diversificação da utilização dos recursos didáticos torna-se de suma importância para criar motivação e interesse dos alunos por disciplinas científicas, sendo notório o interesse dos alunos quando esses métodos são aplicados de forma correta e instigante.

\section{Referências}

Augusto T.G.da S., Amaral I.A. 2014. Concepções de professoras das séries iniciais, em formação em serviço, sobre a prática pedagógica em ciências. Investigações em Ensino de Ciências, 19(1) 163176. 2014.

Bacci D.de L.C., Silva D.B.da, Silva D.G.da, Silva K.B.V.da, Saito R.S. 2013. Ensino de Geociências no contra turno escolar. In: Enc. Nac. Pesq. Educ. Ciências, SP, 9, 2013. Atas do IX Encontro Nacional de Pesquisa em Educação em Ciências - SP, Águas de Lindóia 2013.URL: < http:/ / www.nutes.ufrj.br/abrapec/ixenpec/atas/resumos/ R1422-1.pdf> Acesso: 04.06.2015.

Berbert O.C. 20076. - Ciências da Terra para a sociedade: o Ano Internacional do Planeta Terra2008. O Ano Internacional do Planeta Terra. Revista 
USP, 71:70-80.

Bianconi M.L., Caruso F. 2005. Educação não-formal. Ciência e Cultura [online], 57(4): 20-20.

Brasil. Ministério da Educação. Secretaria de Educação Média e Tecnológica. 1998. Parâmetros Curriculares Nacionais. URL: <www.mec.gov.br/pcn> Acesso: 10.05.2015.

Carneiro C.D.R., Toledo M. C. M.de, Almeida F.F.M. 2004. Dez motivos para a inclusão de temas de geologia na educação básica. Rev. Bras. Geoc., 34(4):553-560.

Compiani M. 1996. As Geociências no Ensino Fundamental: um estudo de caso sobre o tema "Formação do universo". Campinas: Educação. Univ. Estadual de Campinas. 225 p. (Tese. Doutorado).

Costoldi R., Polinarski C.A. 2009. Utilização de recursos didático-pedagógicos na motivação da aprendizagem. Programa de Pós-Graduação em Ensino de Ciência e Tecnologia. I Simpósio Nacional de Ensino de Ciência e Tecnologia - PR, Curitiba 2009. URL: < http://www.sinect.com.br/ anais2009/artigos/8\%20Ensinodecienciasnasseriesiniciais/Ensinodecienciasnasseriesinicias_Artigo2.pdf. > Acesso: 20.05.2015.

EBC Agência Brasil. URL: <http://agenciabrasil.ebc. com.br/educacao/noticia/2015-01/mp-rj-discute-qualidade-da-educacao-basica-em-duque-de-caxias >. Acesso: 14.08.2015.

Figueiredo B.R. 2007. O Ano Internacional do Planeta Terra. Jornal da Unicamp, 364 (2). 2 a 15 de julho de 2007.

Firmino A.R.de S., Bezerra H.P.A., Santos M.do C.P., Rodrigues A.P.de C., Rangel J. 2013. A importância de aulas experimentais nos conteúdos de Geociências abordados na disciplina de Biologia no Ensino Básico. Revista Eletrônica Novo Enfoque, 17(17): $100-105$.

França B.A.de 2009. A utilização de recursos didáticos nas aulas de geografia em escolas da zona oeste do rio de janeiro. In: França, A. B. (Ed). $10^{\circ}$ Encontro Nacional de Prática de Ensino em Geografia - RS, Porto Alegre: 2009. URL: < http:// www.agb.org.br /XENPEG/artigos /Poster / P \% 20(6).pdf> Acesso: 01.06.15.

Fraser M.T.D., Gondim S.M.G. 2004. Da fala do outro ao texto negociado: discussões sobre a entrevista na pesquisa qualitativa. Paidéia (Ribeirão Preto) [online], 14(28): 139-152. Maio/ Agosto 2004.

Frodeman R., Turner C. 1996. Geology in a post-industrial society. J. Geosc. Educ.,44(1): 36-37.

Galvão D.M., Finco G. 2009. Geociências no Ensino Médio: Aprendendo para a cidadania. In: Encontro Nacional de Pesquisas em Educação em Ciências, 7, Florianópolis, SC, 2009. Anais... Santa Catarina: Univ. Fed. Santa Catarina. URL: <http://posgrad.fae.ufmg.br/posgrad/viienpec/ pdfs/1437.pdf> Acesso: 16.05.2015.
Guimarães I.M.A. 2004. Contribuição da geologia na construção de um padrão de referência do mundo físico na educação básica. Revista Brasileira de Geociências, 34(1): 87-94.

Imbernon R.A.L., Sígolo J.B., Toledo M.C.M.de 1994. Análise crítica dos conhecimentos em Geociências de Alunos de $1^{\circ}, 2^{\circ}$. e $3^{\circ}$. Graus e professores de $1^{\circ}$ e $2^{\circ}$. Graus. Primeiros resultados. Cadernos do IG/UNICAMP, v. esp. (2): 3-10.

Instituto Brasileiro de Geografia e Estatística. Informações completas: Rio de Janeiro - Duque de Caxias. URL: <http://www.cidades.ibge.gov.br/ xtras/perfil.php?lang $=\&$ codmun $=330170$ \&sear $\mathrm{ch}=$ rio-de-janeiro $\% 7 \mathrm{Cduque}-\mathrm{de}-$ caxias $>$. Acesso: 06.08.2015.

Jesus A.C.A. 2010. Como aplicar jogos e brincadeiras na educação infantil. Rio de Janeiro: Bransport. 100p.

Lopes O.R., Carneiro C.D.R. 2009. O jogo "Ciclo das Rochas" para ensino de Geociências. Rev. Bras. Geoc., 39(1):30-41.

Marques L., Praia J. (coords.) Geociências nos currículos dos ensinos básico e secundário. Aveiro: Univ. Aveiro, p. 93-114.

Menezes M.B. 2013; A relevância dos conteúdos geocientíficos no ensino fundamental, em realengo, zona oeste, do estado do rio de janeiro. Rio de Janeiro: Esc. Ciênc. Saúde. Univ. Castelo Branco. 33p. (Monog. Graduação).

Oliveira D.K., Antunes M.da S., Soares B.M. 2012. Saída de campo: Atividade que possibilita explorar uma diversidade de conteúdos no meio ambiente. In: Congresso Internacional de Educação Cientifica e Tecnológica, 2, Santo Ângelo, RS, 2012. Anais... Rio Grande do Sul: Universidade Regional Integrada Santo Ângelo. URL: < http://www. santoangelo.uri.br/ciecitec/anaisciecitec/2012/resumos/REL_EXP_PLENARIA/ple_exp23.pdf $>$ Acesso: 04.06.2015.

Oliveira O.B.de, Trivelato S.L.F. 2006. Práticas docente: o que pensam os professores de ciências biológicas em formação. XIII Encontro Nacional de Didática e Prática de Ensino - PE, Recife: 2006. Univ. Fed. Pernambuco. URL: $<$ http://www.periodicos.proped.pro.br/index. php/revistateias/article/view/187/186> Acesso: 02.06.2015.

Orion N. 2001. A educação em Ciências da Terra. Da teoria à prática-implemantação de novas estratégias de ensino em diferentes ambientes de aprendizagem. In: Marques L., Praia J. Org. 2001. Geociências nos currículos dos ensinos básico e secundário. Aveiro: Univ. Aveiro, p. 93-114.

Orion N., Thompson D.R., King C. 1996. Educação em Geociências: uma dimensão extra para a educação cientifica escolar. Cadernos do IG/UNICAMP, 6: 122-133.

Piranha J.M., Carneiro C.D.R. 2009. O ensino de 
geologia como instrumento formador de uma cultura de sustentabilidade. Rev. Bras. Geoc., 39(1): 129-137.

Rios I.Q., Chaves J.M. 2011. Exercício pedagógico e ensino de Geociências nas escolas de Feira de Santana-BA: Análise do uso da música como ferramenta didática. In: Semin. Inic. Cient. Univ. Est. Feira de Santana, BA, Feira de Santana: 2011. Bahia: Univ. Est. Feira de Santana. URL: <http://www2.uefs.br/semic/upload/2011/2011XV-043IRI670-090.pdf> Acesso: 01.06.2015.

Seniciato T., Cavassan O. 2004. Aulas de campo em ambientes naturais e aprendizagem em ciências - um estudo com alunos do ensino fundamental. Ciência \& Educação, 10(1):133-147.

Silva A.V.P. 1998. A construção do saber docente no ensino de ciências para as séries iniciais.In R. Nardi. Org. 1998. Questões atuais no ensino de ciências. São Paulo: Escrituras, p. 33-41.

Silva M.do A.dos S., Soares I.R., Alves F.C., Santos M.de N.B.dos 2012. Utilização de Recursos Didáticos no processo de ensino e aprendizagem de Ciências
Naturais em turmas de $8^{\circ}$ e $9^{\circ}$ anos de uma Escola Pública de Teresina no Piauí. In: Connepi, 7, Palmas, TO, 2012. URL: < http://propi.ifto.edu.br/ocs/index.php/connepi/vii/paper/viewFile/3849/2734> Acesso: 02.06.2015.

Souza S.E.de 2007. O uso de recursos didáticos no ensino escolar. In: I Enc. Pesq. Educ., IV Jorn. Prát. Ensino, XIII Sem. Pedag. UEM: "Infância e Práticas Educativas". URL: < http://www.pec.uem.br/ pec_uem/revistas/arqmudi/volume_11/ suplemento_02/artigos/0 19.df.> Acesso: 20.05.2015.

Toledo M.C.M.de, Macedo A.B., Machado R., Martins V.T.de S., Riccomini C., Santos P.R.dos, Silva M.E.da, Teixeira W. 2005. Projeto de Criação do Curso de Licenciatura em Geociências e Educação Ambiental - IGc/USP. Geologia USP, Public. Espec., 3:1-11.

Weissmann H. 1998. O que ensinam os professores quando ensinam ciências naturais e o que dizem querer ensinar.In H. Weissmann Org. 1998. Didática das Ciências Naturais: contribuições e reflexões. Porto Alegre: Artmed, p. 31-55.

Resumo: Este estudo realizou um diagnóstico sobre o ensino de temas geocientíficos no sexto ano do ensino fundamental II, em instituição educacional da rede privada, Santa Cruz da Serra, Duque de Caxias-RJ. Questionários foram aplicados a um docente de Ciências e 37 discentes. Uma avaliação qualitativa de quatro diferentes metodologias de ensino sobre o ciclo da água foi realizada. A maioria dos discentes não soube dizer o que era Geociências, mas relatou alto interesse por Universo, Vulcanismo e Planeta Terra. Tanto o docente quanto os discentes apontaram os ciclos biogeoquímicos como temas menos interessantes. Das atividades aplicadas em sala de aula, as atividades lúdicas (jogo e modelo didático) foram as que fomentaram maior número de questionamentos. É necessário que os professores das séries do ensino fundamental II, em especial de Ciências e Geografia, se atualizem e diversifiquem as práticas de ensino para proporcionar uma melhor construção do conhecimento pelos discentes.

PALAVRAS-CHAVE: Geociências, práticas de ensino, recursos didáticos. 